\title{
10
}

\section{Developments IN PACIFIC ISLANDs' AIR TRANSPORT}

Christopher Findlay, Peter Forsyth and John King

South Pacific regional aviation has faced a range of problems for many decades. These have been documented and analysed, for example by the World Bank (1993), Forsyth and King (1996) and most recently by the Pacific Regional Transport Study (Pacific Islands Forum Secretariat 2004).

The core problem facing the Pacific region is one of low density and remoteness - the region has long thin, aviation routes, and these are inherently costly to serve. This problem of low density reflects geography, low population and the size of tourism markets. However, new developments on both the supply and demand sides of the market may offer options for challenging some of these constraints. Furthermore, there is evidence of greater interest in removing some of the policy impediments to change.

\section{OLD PROBLEMS}

In aviation, there are substantial economies of density. Larger aircraft are, per passenger, cheaper to operate. In addition, there are economies on the indirect cost side as well. Routes that serve few passengers either have to be operated by aircraft that are small and have high per passenger costs, or they can be operated with larger aircraft but only at low frequencies. Importantly, traffic is sensitive to frequency, especially business travel. At the same time, good schedules, which enable low connection times and fit in with infrastructure (such as hotel) availability, are important for tourist travel. 
The overall small scale of operations means that the range of aircraft types is limited. Thus airlines tend to operate aircraft types which are suitable for some routes but not for others, for example, a mid-sized Boeing 737 may be optimal for Nadi to Wellington but when operated Nadi to Apia, it can only operate infrequently as the route lacks density.

Low density is more of a problem on routes within the region than to and from it. Inevitably, fares within the region are high relative to fares in more dense markets. In addition, several of the routes within the region are quite long, also adding to the cost. Low frequencies mean that connections are poor, making travelling around the region difficult and multiple country visits unattractive to tourists.

Low density also affects travel to the region from the Pacific Rim countries. The smaller island countries have medium-sized aircraft providing the linkage and whilst fares are reasonable for tourism markets, the airlines sustain very small fleets (Air Vanuatu and Polynesian each having only 1 jet aircraft) and thus typically provide sub-optimal schedules. Fiji has some moderately dense routes and is comparatively well served, with services in larger aircraft such as Boeing 747 or 767 aircraft, which are able to reap the economies of large-scale aircraft.

So far, there has not been much development of hub and spoke networks, especially for traffic from outside the region. Hub and spoke networks enable higher density routes, but they require good connections, high frequencies and well coordinated service, which are difficult to achieve. In addition, the length of some routes in the region lessens the advantage of hub and spoke operations over point to point services.

It can be seen there are inherent difficulties in aviation in the Pacific region: geography, population and aviation technology all make it inevitable that services are relatively high cost and inconvenient (this is true not just for aviation, but also for other aspects of transport and communications, such as shipping and telecommunications). In addition, the region is beset with a range of other obstacles. Some, though not all of these, can be addressed and include the following.

\section{Diseconomies of small fleets}

Many of the airlines in the region are very small, and operate small fleets. They are not able to gain the economies of fleet size. To serve very diverse markets 
they may have several aircraft types, which in turn prevents them from gaining the economies of having only one or two aircraft types. The small fleets mean that they have no back-up aircraft, contributing to unreliability of services should any aircraft be out of service.

\section{Restricted traffic rights}

International air services in the Pacific region are governed by bilateral agreements, which considerably restricts the ability of an airline based in one country to operate and market its services between other countries. Thus it may make good sense for an airline from country A to fly to $\mathrm{C}$ via $\mathrm{B}$, but, if it cannot carry traffic from $\mathrm{B}$ to $\mathrm{C}$, the flight may not be viable. Bilateral restrictions make it very difficult for an airline to operate a hub outside its own country. This encourages point to point services, which are less frequent and more costly.

\section{Limited competition}

The low densities on most routes make the development of strong competition unlikely. However, policy also restricts competition. As a result, airlines are less open to the threat of competition than they need be, and thus are under less pressure to perform.

\section{Poor financial performance of airlines}

Pacific airlines have long sufered financial instability. Some airlines have performed poorly for decades, leading to the cancelling of services, difficulties in funding new investment, and protectionist pressures. Most of the airlines of the region are publicly owned, but the institutional framework within which they operate is usually ill defined. Although airlines obtain financial support from their government owners, it is not on any systematic or conditional basis, often resulting in chronic underperformance, periodic crises, and occasional collapses. Crises and collapses are not unique to the South Pacific, but they are particularly costly in this region where the alternative transport options are scarce. The risk of these crises is increased by an institutional structure that does not set clear incentives to meet policy objectives, and frequently does not even have objectives.

Many of these problems have been recognised for a long time, and attempts have been make to limit them. In practice, the region's airlines have established 
many strategic alliances to overcome the problems of remoteness, small scale and low density (see Forsyth and King 1996). Over time, technical cooperation between airlines has developed. The airlines were early in their use of code shares and joint services to enable individual airlines to build up viable networks and schedules. As with all strategic alliances, there is a trade off between gains from greater cooperation and lessened opportunities for competition. However, cooperation between airlines has lessened the problems of their operating environment. It is possible that better institutional and ownership arrangements will encourage further cooperation and shared problem-solving.

Airport and related infrastructure is another issue confronting the Pacific island countries. As elsewhere, the problem is getting the level of investment right. Too little investment will mean inadequate infrastructure. This will impose costs on users. For example, inadequate runways will force airlines to use less suitable, higher-cost aircraft to serve a destination, or they may require airlines to operate flights less than fully loaded, leading to higher costs. Poor terminal facilities will impose costs of discomfort on passengers, and they will make it difficult to make the most of retail opportunities. On the other hand, if infrastructure is excessive, costs will be too high. Governments will have to provide subsidies to fund losses, or charges to users will be unnecessarily high. In the first instance, airlines will pay, but they will pass the higher costs on to passengers. The ultimate result is reduced opportunities for the community in which the airport is located. The issue of getting investment right has been highlighted by the growth of low-cost carriers which usually wish to make use of fairly simple but cheap terminal facilities. Some airports such as Singapore Changi, for example, are building simple, low-cost terminals to satisfy the requirements of low-cost carriers.

\section{RECENT DEVELOPMENTS}

There are important forces for change in aviation policy in the region. Conditions now are significantly different compared to those as little as two years ago, even though many of the usual problems remain.

Attitudes to financial problems are changing. In 2003, four airlines reported a combined loss of $A \$ 19.94$ million and three airlines made a combined profit of $A \$ 35.34$ million. Several airlines have not been profitable for some time. In 2002 , five airlines made a combined loss of $A \$ 30.11$ million and three airlines made a combined profit of $A \$ 6.11$ million. In the past, governments absorbed 


\section{2

these financial burdens, but their capacity to continue doing so has declined. The recent shutdown of Royal Tongan and the restructuring of Polynesian Airlines are illustrations of the tightening budget constraints.

Donors also now say they are reluctant to continue to provide support to economies of the region if government budgets are run down by airline lossesa situation that contributed to support by Australia for the recent Regional Transport Study (Pacific Islands Forum Secretariat 2004).

The shift in political attitude to the airline positions was reinforced in August 2004 when Forum Leaders adopted a set of regional transport principles, a theme of which is a commitment to commercial orientation and good governance in airline operations and related infrastructure. These principles are listed in an appendix to this chapter.

Another development is the design of a new region-wide air services agreement (Pacific Islands Air Services Agreement), currently being adopted but yet to be ratified and implemented (a minimum of 6 ratifications is required, and this target is expected to be achieved, although debate on the policy will continue between the signature and ratification points in the participating economies).

Further drivers of policy change come from the markets themselves. The level of competition on routes to the region has increased as a consequence of the entry of so-called 'low-cost carriers', such as Pacific Blue and Freedom Air. Implementation of the bilateral agreements on market access in the region has been flexible, as illustrated by introduction of these new opportunities, as well as a long history of various forms of inter-airline cooperation in the region. However, higher levels of competition on routes to the region make it more difficult to sustain profits, which offset losses on other services within the region. This also adds to the budget pressure on governments who want to sustain their own airline.

Expectations imposed on the airlines often extend beyond flying operations. They are expected to provide services which support other sectors of their economies (tourism for instance), maintain connectivity within economies by offering services to remote areas, and to maintain connectivity within the group of economies as a whole. In some cases, they also serve to support the nation status of their home economy. Many of these concerns are acute for smaller economies. But, as noted, the capacity to reach this mix of policy targets is challenged by developments in the market place. 
Another change, on the supply side, is the development of new aircraft technology that offers options for jet services of 30-90 seats. Smaller jet (rather than turbo-propelled) aircraft operate at higher frequency (to which travel demand responds significantly in other markets) than offered by the midsized jets currently employed, offering new opportunities for developing routes within the region. Industry observers are cautiously optimistic about the prospects for the introduction of these aircraft in the region.

Expectations are now widely held for growth of tourist traffic from AsiaChina and India in particular - to the Pacific region. While some economies in the region welcome the prospect of rapidly rising tourist numbers, others are concerned about the impacts on local economies. The very small economies, who offer highly differentiated and distinct holiday experiences, often based on environmental features, are concerned about their ability to sustain their position in the market at the same time as establishing links with these increasingly important origin countries.

There may be returns from working together on developing strategies for the new Asian markets. This could include sharing information on forecasts, identifying the services likely to be sought, analysing options for meeting the demand, reviewing programs in training institutions, and noting the role of foreign investment, including the hotel sector and perhaps from the home countries of the visitors.

Cooperative work in this area should add to policy advisors' capacity to make assessments of the implications of tourism industry measures, including a variety of both taxes and subsidies, as well as other regulatory measures. This includes a deeper understanding of the role of, costs of support for, and protection of, airline operators for tourism industry development.

In this chapter we offer an extensive discussion of four policy related aspects of this set of issues, namely, the impact of the Pacific Islands Air Services Agreement, the entry of low-cost carriers, the moves to privatisation and the questions of infrastructure development. We conclude with some remarks on what we regard as the key elements of the policy agenda in this sector for Forum island countries.

\section{PACIFIC ISLANDS AIR SERVICES AGREEMENT (PIASA)}

The Pacific Islands Air Services Agreement was developed at the request of Pacific islands forum Ministers in 1998 and was finally endorsed for signature 
at the 2003 Pacific Forum Leaders meeting. Its objectives were to establish a framework for a transition to a 'single market'. Six parties must ratify the agreement before it comes into force. Five nations (Samoa, Tonga, Nauru, Vanuatu and Cook Islands) have so far signed the agreement and one more economy is expected to join that group shortly. The critical issue is the nonadherence to the agreement by Fiji.

The Pacific Islands Air Services Agreement is more liberal than many other plurilateral agreements, especially in its treatment of designation (the equivalent in this setting of trade in services as a rule of origin for trade in goods). A better specified accession clause would add to the agreement's degree of openness.

The Forum island countries agreed that it was desirable to open their own markets before integration with other countries, although the parties may agree to extend the agreement to others subject to further negotiation and to the consent of all members. The terms of accession are therefore in the hands of the current membership, rather than being specified at the foundation of the agreement and there is the risk that the current membership, at some point, will decide to close the membership in order to limit the competitive effects of further entry.

Rather than being subject to the consent of all existing parties, a more liberal form of this clause would be to say that the members are obliged to accept new members as long as they meet the same conditions as existing members.

The Air Services Agreement is to be implemented in three phases. The first phase commences six months after the agreement comes into force and liberalises the third, fourth and sixth 'freedoms' (that is, services between the parties - see Table 10.1). In the second phase, starting at 12 months, the fifth 'freedoms' amongst the parties are liberalised. Thirty months after the agreement comes into force, the fifth freedoms on routes to non-members of the agreement are open to all member airlines (subject to the bilateral agreements with the non-member states). Australia and New Zealand may accede to the agreement only at the beginning of the third phase. Wet leasing (of aircraft and crew) is permitted and there is no price regulation. However, domestic services (rights of cabotage) are excluded.

The terms of designation (of airlines with access to the terms of the agreement) vary between the stages of implementation. In the first stage, designated airlines must be 'substantially owned and effectively controlled by 
one or more of the Parties to the Agreement and/or their nationals'. This clause is relatively liberal since, even though it imposes the usual ownership and control clause, it also permits accumulation of ownership shares among the members.

The first stage also allows for the case where the ownership of the airline shifts outside the parties: an airline can be designated as long as it is then 'effectively controlled' by the parties and has its principal place of business in the territory of the designating party. Further, if the party does not own/ control an airline when the agreement comes into force, it can designate another which has its principal place of business in the territory of the party.

These clauses are especially relevant as countries within the Pacific region effectively designate foreign-owned carriers to operate on their routes. For example, the restructuring of Polynesian Airlines has led to the establishment of a new airline-Polynesian Blue-a joint venture with Virgin Blue but majority owned by Polynesian interests ( 49 per cent by the government, 2 per cent by a local investor). The new airline (to be operated by Pacific Blue out of New Zealand) will take over the international routes of the previous Polynesian Airlines while the latter will retain its turbo-prop regional operations.

From stage 3, designation is even more liberal. A designated airline can meet either the ownership and control clause of the principal place of business test. These terms of designation not only reduce barriers to entry, they also make it easier for airlines in the region to be consolidated without losing their rights of market access. In the third stage, equity funding can also be raised from outside the region and the rights of market access maintained, as long as the airline is based in a designating party.

The agreement refers to various 'business' and competition policy matters. It is important to treat these matters explicitly in the absence of other institutions to respond to complaints by an airline located in one party about actions of another party.

The rights of designated airlines to set up offices, bring in staff, do their own ground-handling, sell tickets, remit currency and pay for local expenses in local currency are identified. User charges for airport services, air navigation and security 'may reflect, but shall not exceed, the full cost' and should not be discriminatory.

An article on pricing allows governments - on behalf of their designated airlines-to complain about discriminatory practices, abuse of a dominant 


\section{Table $10.1 \quad$ Freedoms of the air}

First freedom

The grant by country A to country B, for country B's airlines to fly over country A's territory without landing.

Second freedom

The grant by country A to country B, for country B's airlines to land in A's territory for non-traffic purposes (eg refuelling, aircraft maintenance).

Third freedom

The grant by country A to country B, for country B's airlines to carry traffic from B to A.

Fourth freedom

The grant by country A to country B, for country B's airlines to carry traffic from A to B.

Fifth freedom

The grant by country A to country B, for country B's airlines to carry traffic between country A and any other country, provided that the flight is part of a service that originate or terminates in country B's territory.

Sixth freedom

The grant by country A to country B, for country B's airlines to carry traffic between A and any other country via a point in B's territory.

Note: The sixth freedom is a combination of a third and fourth right (for example, see below)

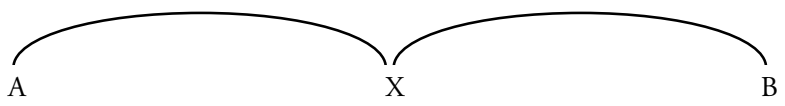

Passengers from $\mathrm{A}$ to $\mathrm{B}$ via $\mathrm{X}$ on a carrier designated by $\mathrm{X}$ is travelling on a fourth freedom service from A to $\mathrm{X}$ and a third freedom from $\mathrm{X}$ to $\mathrm{B}$. Sixth freedom traffic is assumed and not specifically negotiated.

position, as well as direct or indirect subsidies. Other items for complaint are fares below cost or the addition of 'excessive capacity or frequency', as long as these practices are sustained rather than temporary, cause 'significant economic damage' and have the 'apparent intent or probable effect' of driving another airline from the market.

Disputes are resolved by setting up a panel, drawing on a list of experts maintained by the International Civil Aviation Organisation (but according to rules and principles that the parties agree when they set up the panel, for example, on the question of whether the panel's decision is binding or whether they seek a resolution of facts).

The Air Services Agreement has been the subject of much discussion in the Pacific region. The most recent assessment was reported in the Pacific Regional 
Transport Study (PRTS) in which the study team argued that an important reason for supporting a regional agreement was that it would add to the pool of potential entrants to routes within the region (a very high proportion of which are currently served by only one carrier). The transport study also noted some points to be clarified in the Pacific Islands Air Services Agreement text but concluded that

...considerable effort has been made recently in negotiating a Pacific Islands Air Services Agreement (PIASA). Whilst it has support from most FICs there are some reservations notably from Fiji. There are also certain points that may require clarification. Given the resources that have gone into PIASA the study team recommended the following:

Recommendation R2: Pacific Forum Members should renew efforts to obtain a workable and strengthened Pacific Islands Air Services Agreement (PIASA) that is supported by all countries in the region. Negotiations to achieve a workable agreement should be conducted through the PIF.

The study team further recommends that Forum island countries examine the option of negotiating an agreement that would expand cabotage to a regional concept.

A significant group of Forum countries is interested in joining the agreement. Their participation may provide them with some important 'first mover' advantages in more open markets in the region. It is possible that new hubs will emerge, perhaps at Apia in Samoa to the West or Port Vila in Vanuata to the East, whose role would be supported by an arrangement which included those points.

Fiji is currently the central node of the regional network. This gives its carrier substantial advantage. The agreement opens the scope for restructuring the networks and therefore challenges Fiji's position.

Figures 10.1 and 10.2 show the route structure into the Pacific island region and within the region respectively. The figures show the key role now played by Fiji, supported by its location. Figure 10.3 shows the traffic volumes to selected destinations from Australia: Fiji data are plotted against the left-hand scale and all others against the right.

These data suggest that Fiji is in a strong bargaining position. Competition from other destinations may eventually draw Fiji into the agreement, and the most likely competitor is now Samoa (discussed further below). In the shorter term, however, negotiation to encourage Fiji's entry is likely to be more effective than competition for that purpose. Options for designation of the Fiji based 
Figure 10.1 Routes to the Pacific region

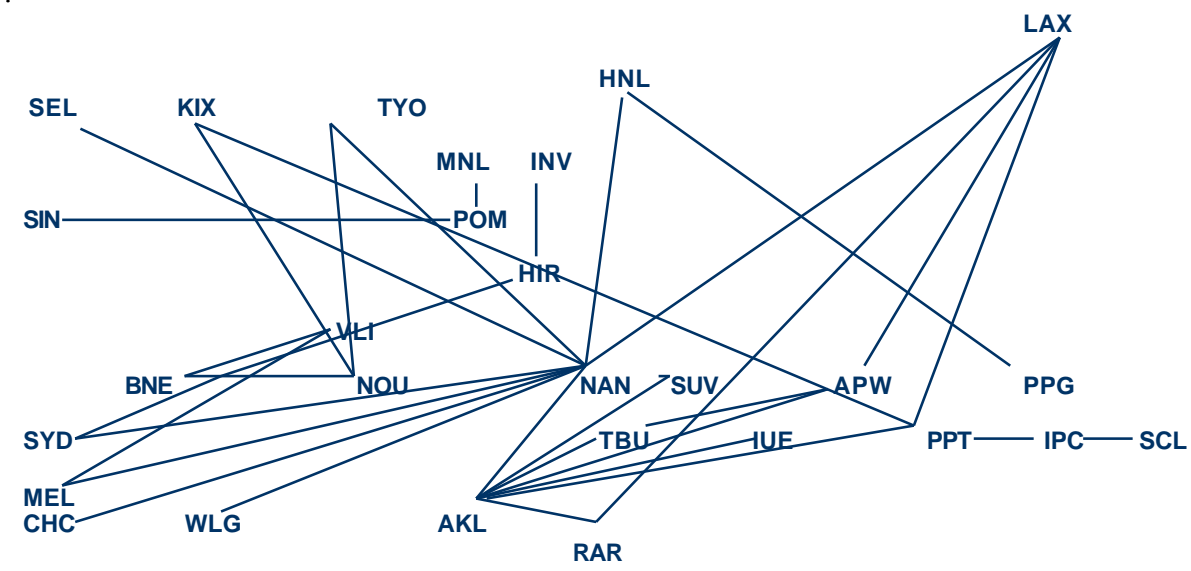

Figure 10.2 Routes within the Pacific region

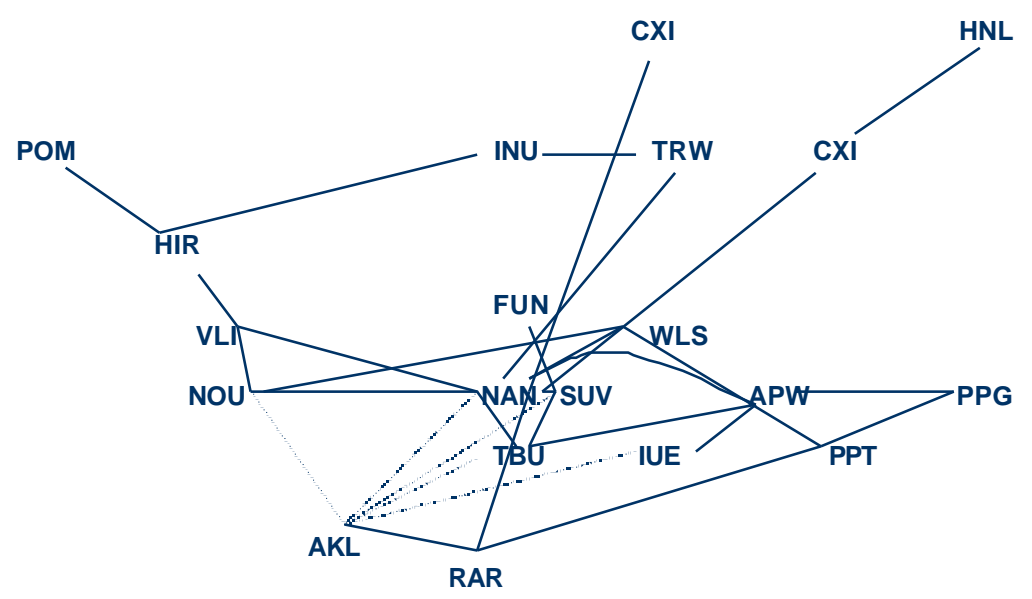

airline, Air Pacific, by other countries in the region which is possible under the terms of a strengthened Pacific Islands Air Services Agreement are some of the talking points that may draw Fiji into the agreement. 'Outer' countries, like the Cook Islands or Vanuatu may be candidates for such discussions. Also of interest is that the Solomon Islands (not yet a signatory to the agreement) has 
Figure 10.3 Outbound monthly passengers from Australia

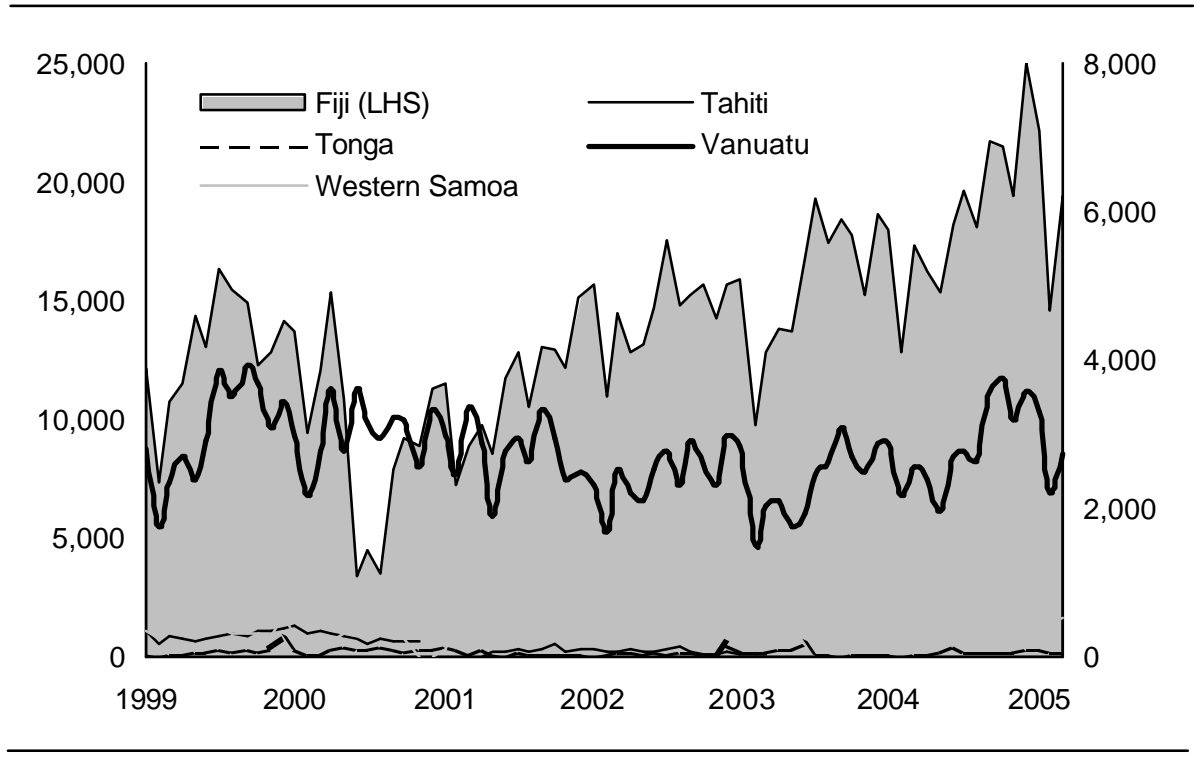

Source: Bureau of Transport and Regional Economics, 2003. International City Pairs Time Series 1999Current, Department of Transport and Regional Services, Canberra. Available from http:// www.btre.gov.au/statistics/aviation/international_time_series_downloads.aspx.

already designated Air Vanuatu on limited routes and has wet-chartered aircraft on the Australia route from both Air Vanuatu and Air Nauru.

No significant empirical study of the costs and benefits of the Pacific Islands Air Services Agreement, based on its text, has yet been made. Work of that type in the context of various scenarios for industry development (such as tourism growth outlooks, the impact of new technology, the effects of operations by low-cost carriers, for example) would assist the policy debate in the region, and help develop the arguments for Fijian participation. AusAID is now funding such a study.

The sorts of effects which might be examined in this study have been identified in early work by the Productivity Commission (Gregan and Johnson 1999) on the effects on competition of this type of plurilateral agreement. The effects could be significant, and not just within the networks affected. There are gains, first, from the effects on competition within the network covered by the club, contributing both to lower margins over costs and also to a movement of actual costs closer to the 'frontier' levels. Second, cost savings are available 
within the membership from new options for network design, including new hub points. These advantages also spill over into higher levels of competitiveness on routes not covered by the club agreement.

Regulatory reform within a route (even though barriers to entry by third parties remain) can have significant effects on performance. Micco and Serebrisky (2004) examine the determinants of air freight rates on routes to and from the United States. As they explain, during the 1990s, the United States implemented a series of Open Skies agreements (which liberalise entry and capacity of carriers eligible for designation). They examined air freight rates on routes with and without such agreements and found that the agreements reduced costs by 8 per cent. However, they also found that other policy-related variables were more significant influences on performance, such as infrastructure capacity and quality of regulation. In their sample 'an improvement in airport infrastructure from the 25 th to 75 th percentiles reduce(d) air transport costs by 15 percent. A similar improvement in the quality of regulation reduce $(\mathrm{d})$ air transport costs by 14 percent.'

There is value in documenting how implementation of the Pacific Islands Air Services Agreement affects participants and non-menbers in the region. Similar agreements in the rest of the world have been difficult to implement, and a dialogue on that experience would be valuable, perhaps begining with a review of experience in Africa and South America. The ASEAN economies are also considering a similar approach to reform of aviation arrangements.

In a related development, a couple of the Pacific Islands Air Services Agreement members have also joined the Multilateral Agreement on the Liberalization of International Air Transportation (MALIAT), current membership of which is Singapore, New Zealand, United States, Chile, Brunei, Samoa and Tonga (see http://www.maliat.govt.nz). Parties to the agreement have the rights to unlimited capacity for their designated airlines on routes among the members. This creates, for example, the opportunity for an airline designated by Samoa under the agreement to fly across the Pacific to the United States or to Chile, also with links in the other direction to Singapore (the latter potentially being an important gateway for Asian tourism growth into the region). This option, plus the recent restructuring of Polynesian Airlines by Virgin Blue bolsters the options for Samoa to emerge as a competitor hub for Fiji in the region, though its easterly geographic position limits the network options. 


\section{LOW-COST CARRIERS}

Low-cost carriers are now operating on routes to Fiji, Cook Islands and Vanuatu. Recent developments are summarised in Table 10.2.

Ergas and Findlay (2004a) suggest some key differences in the business model implemented by low-cost carriers (or 'value-based airlines' as they call them):

Firstly, value based airlines usually have lower costs than full service carriers. Their business model is based on features such as the use of online reservation systems, the development of star-structured networks (that is, point to point, short haul operations) with a simple fleet composition, no interlining, and single class cabins. They start from a low 'greenfields' cost base and the structure of their operations is such that the turnaround times of their aircraft are typically shorter than those of full service carriers.

Secondly, the relative simplicity of their business model also extends into the realm of pricing. While value based airlines use 'yield management' to maximise their profits, the range of fares they offer tends to be narrower than that offered by full service carriers.

Thirdly, value based airlines also differ in the extent to which they seek to attract high yielding business travellers. Value based airlines typically adopt different business and marketing strategies (including frequencies and lounge facilities) relative to rival full service carriers, for whom attracting business travellers is particularly crucial. This is not to imply that value based airlines do not target business travellers-they must do so to be viable. But the approach they use can, and usually does, differ from that employed by full service airlines.

Ergas and Findlay (2004) argue that the competitive threat from low-cost carriers is likely to be significant. Their flat fare range means that they can discount heavily with less fear of cannibalisation of higher fare tickets. That is,

...the relatively flat fare ranges (of the LCCs) are equivalent to a commitment to having low opportunity costs from replacing the sale of an uncertain but potentially higher priced fare later by the sale of a certain but lower priced fare now.

On the other hand, full-service carriers as a result of their application of yield management strategies have a wider range of fares and have less incentive to engage in vigorous price competition. To some extent, they must meet the competition, but these effects limit their response and also the extent to which they can recoup contributions to common costs by charging higher fares to higher-yielding passengers.

Ergas and Findlay (2004) also explain how the value-based airlines can 'cherry pick' and earn a contribution to common costs from customers who can be 
Table 10.2 Low-cost carriers' Pacific entry and capacity

\begin{tabular}{|c|c|c|c|c|c|c|c|}
\hline Carrier & $\begin{array}{l}\text { Route } \\
\text { (all return) }\end{array}$ & Entry & $\begin{array}{c}\text { Initial } \\
\text { weekly } \\
\text { frequency }\end{array}$ & $\begin{array}{c}\text { Initial } \\
\text { weekly } \\
\text { capacity }\end{array}$ & $\begin{array}{c}\text { Subsequent } \\
\text { weekly } \\
\text { frequency }\end{array}$ & $\begin{array}{c}\text { Subsequent } \\
\text { weekly } \\
\text { capacity }\end{array}$ & $\begin{array}{l}\text { Effective } \\
\text { date of } \\
\text { change }\end{array}$ \\
\hline \multicolumn{8}{|c|}{ Virgin Blue/Pacific Blue } \\
\hline \multirow[t]{5}{*}{ ex Australia } & MEL-VLI & Aug-04 & 1 & 180 & - & - & May-05 \\
\hline & BNE-VLI & Aug-04 & 1 & 180 & 2 & 360 & May-05 \\
\hline & BNE-NAD & Sep-04 & 3 & 540 & 4 & 720 & May-05 \\
\hline & SYD-NAD & Jun-05 & 4 & 720 & 4 & 720 & n.a. \\
\hline & MEL-NAD & Sep-04 & 3 & 540 & 3 & 540 & n.a. \\
\hline ex New Zealand & CHC-RAR & Nov- 04 & 1 & 180 & 1 & 180 & n.a. \\
\hline \multirow[t]{4}{*}{ Freedom Air } & HLZ-NAD & Apr-03 & 1 & 142 & 2 & 284 & Apr-05 \\
\hline & PMR-NAD & Apr-03 & 1 & 142 & 2 & 284 & Apr-05 \\
\hline & CHC-NAD & Apr-03 & 1 & 142 & $2^{*}$ & 284 & Apr-05 \\
\hline & WLG-NAD & Feb-04 & 2 & 284 & 4 & 284 & Apr-05 \\
\hline
\end{tabular}

Note: *Supplemental services CHC-NAD return 10-24 July.

attracted by lower fares without the package of services that the full service carriers provide.

Air Pacific (on routes to Fiji) responded to low-cost carrier competition by changing its fare structure before the entry of Pacific Blue. Table 10.3 shows the fares from Australia to Fiji (similar changes occurred in fares for travel in the reverse direction). Fares were reduced prior to entry, and by a larger proportional amount for 'initiative fares'. The more open fares received different degrees of discount. 'Top' level fares, on the other hand, increased (a negative sign in the percentage change column indicates an increase).

The experience on routes to Vanuatu was different to that on routes to Fiji. The Air Vanuatu fare structure (other than business class and the little used full economy fare) were 'inclusive tour' fares requiring a bundling of air and ground content. When Pacific Blue commenced operations with its point-topoint unbundled fares, Air Vanuatu responded by introducing unbundled excursion fares for the general public and by establishing volume discounts for tour operators. The fences around 'inclusive tour' fares mean that it is very difficult to compare the fares in the two periods (pre and post Virgin Blue), other than to say that the cost to travellers has fallen, as have yields to Air Vanuatu. 
Table 10.3 Air Pacific fares from Australia to Fiji (return economy, A\$)

\begin{tabular}{|c|c|c|c|c|c|}
\hline & $\begin{array}{l}\text { Pre June- } 04 \\
\text { (A) }\end{array}$ & $\begin{array}{c}\text { Air Pacific } \\
\text { initiated- } \\
\text { June } 2004 \\
\text { (pre-Pacific Blue) }\end{array}$ & $\begin{array}{c}\% \text { decrease } \\
\text { vs }(\mathrm{A})\end{array}$ & $\begin{array}{c}\text { NOW } \\
\text { (post-Pacific Blue) }\end{array}$ & $\begin{array}{c}\% \text { Decrease } \\
\text { vs }(\mathrm{A})\end{array}$ \\
\hline \multicolumn{6}{|c|}{ BNE-NAN } \\
\hline Initiative* & 499 & 368 & 26 & 338 & 32 \\
\hline Bottom\# & 836 & 368 & 56 & 368 & 56 \\
\hline Middle\# & 887 & 788 & 11 & 788 & 11 \\
\hline Top\# & 989 & 1028 & -4 & 1028 & -4 \\
\hline \multicolumn{6}{|c|}{ MEL-NAN } \\
\hline Initiative* & 599 & 498 & 17 & 458 & 24 \\
\hline Bottom\# & 887 & 498 & 44 & 498 & 44 \\
\hline Middle\# & 938 & 888 & 5 & 888 & 5 \\
\hline Top\# & 1040 & 1208 & -16 & 1208 & -16 \\
\hline
\end{tabular}

Traffic volumes to Fiji and Vanuatu are shown in Figures 10.4 and 10.5 respectively (these are extracted from Figure 10.3). A vertical line marks the starting date of the low-cost carrier services. Both series show higher peak traffic volumes following low-cost carrier entry (based on the previous two peak values: values in trough months appear to lie on the same trend as previous values). Also of interest is that the usual mid-year peaks in traffic to Fiji appear to have been delayed by expectations of low-cost carrier entry. The significance of the impact of low-cost carrier entry on total traffic volumes is less clear and a more powerful test depends on access to a longer timeseries.

As suggested by the fare data in Table 10.3, there were different patterns of response by incumbent carriers. The capacity of Air Pacific remained the same following low-cost carrier entry and the airline also managed to maintain its traffic (based on comparisons of data in each month in the 2004-05 period compared to the same month in the 2003-04 period). The low-cost carrier, once established, carried 15-18 per cent of traffic each month (about the same as its capacity share).

On routes to Vanuatu from Australia, the incumbent appears to have increased capacity following entry but then returned to the original level of capacity after five months. After increasing capacity, it carried about the same 
Figure 10.4 Traffic volume to Fiji from Australia

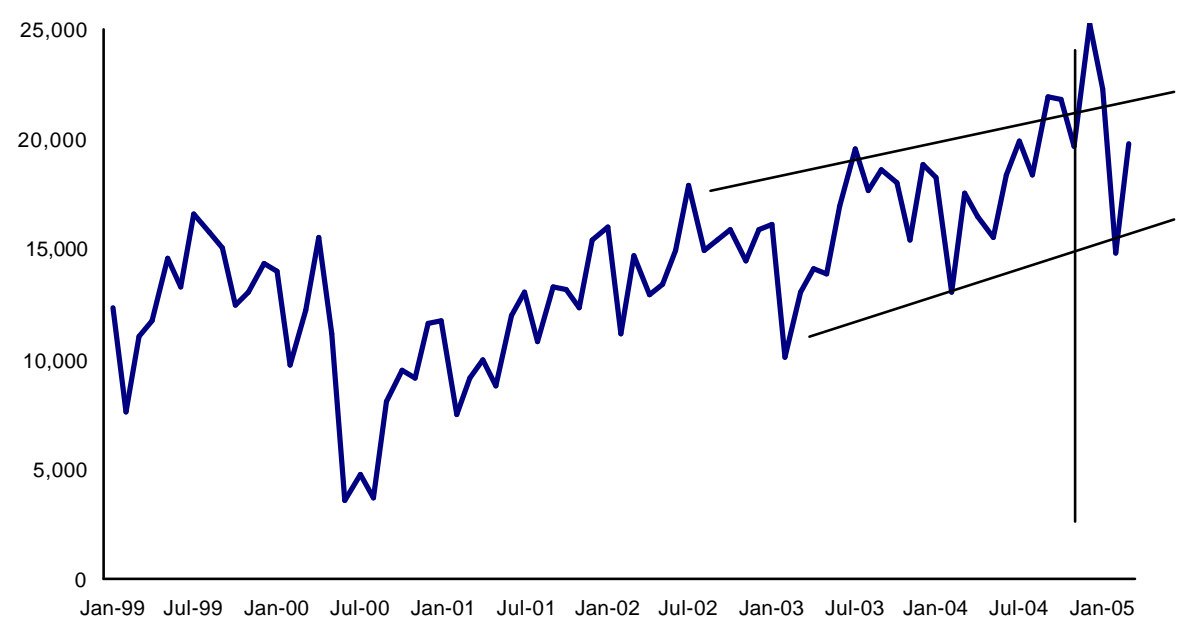

Figure 10.5 Traffic volume to Vanuatu from Australia

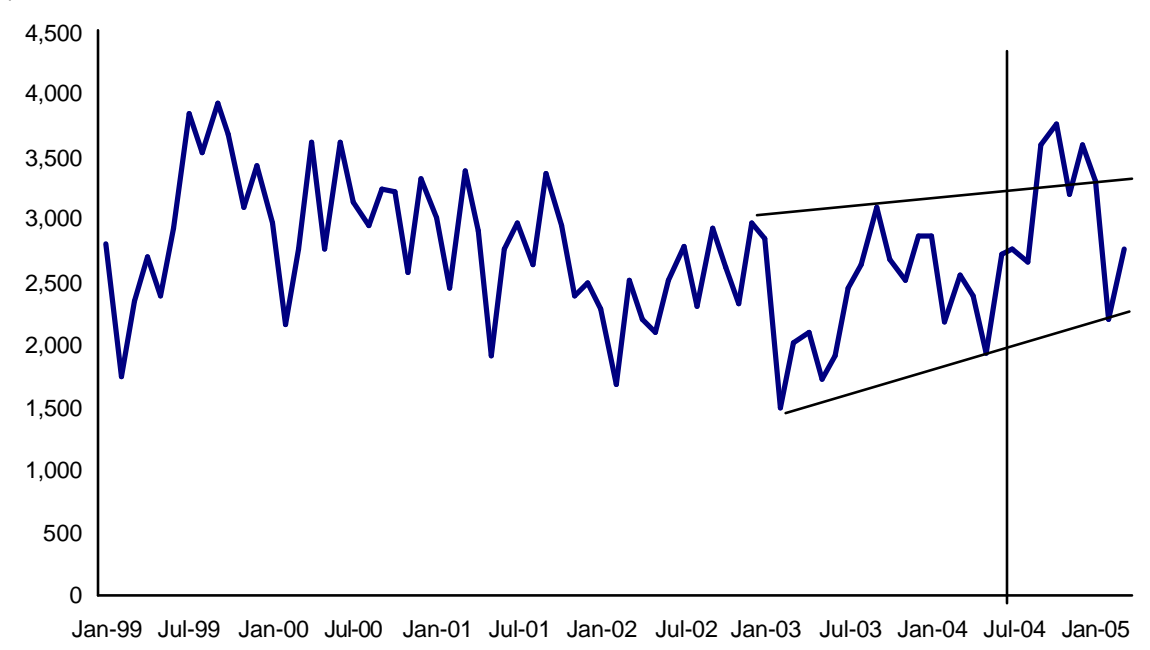

Source: Bureau of Transport and Regional Economics, 2003. International city pairs time series 1999current. Department of Transport and Regional Services, Canberra. Available from http:// www.btre.gov.au/statistics/aviation/international_time_series_downloads.aspx. 
number of passengers as in the same period a year earlier but then its traffic numbers increased in February and March 2005. It has, however, maintained its market share at 73-75 per cent throughout this period.

The discussion of the low-cost carriers' impact, so far, has concentrated on the impact on routes to and from the region. Questions remain about the scope for low-cost carriers to operate within the region. Some of the uncertainties include the following.

- The same problems that have inhibited development within the region also constrain the low-cost carrier operators, such as geography and density, although higher traffic volumes based on Asian tourism may relax some of these constraints.

- The Pacific Islands Air Services Agreement offers options for building new networks, but the absence of Fiji, with its traffic volumes, weakens the business case for low-cost carriers' entry.

- New aircraft options, such as regional jets, may relax some of the constraints, but those aircraft are reported to have relatively high costs per seat $/ \mathrm{km}$ (on the other hand, lower-cost turbo-prop aircraft favoured by some regional airlines have other disadvantages on the relatively long haul routes in this region).

If the low-cost carriers aggressively seek market share, they will put considerable pressure on fare levels, and could lead to a boom in travel. It is not clear, however, whether this strategy is sustainable in the long run. Alternatively, they may seek to gain a small but stable share of a profitable market. To do so, they will need to schedule a small amount of extra capacity, and cut fares to a limited extent.

The experience of Virgin Blue may provide some guidance. At different stages in its past, Virgin Blue was an aggressive competitor, increasing its scheduled capacity quite rapidly. In the past year, however, it has retreated from this strategy, and become much more cautious. It is likely that Pacific Blue will also exhibit this caution. Thus vigorous price wars, such as those that occur in the United States and Europe, are not likely be present in the South Pacific. The growth of low-cost carrier traffic is likely to be more measured (which would be in keeping with the tourism infrastructure constraints in most countries of the region).

Thus, overall, the introduction of low-cost carriers does contribute a little to resolving the old problems facing the region. For those countries that have 
a route density sufficient to attract low-cost carriers, lower fares and greater traffic flows will lessen their degree of remoteness. Smaller tourism destinations, which are not able to attract low-cost carrier services, are not likely to be much helped. Furthermore, the introduction of low-cost carriers is not likely to make much difference to routes within the region. Low-cost models for low density, long routes have not yet been developed, and it has yet to be seen if they are feasible. As is now the case in other regions such as Southeast Asia, the presence of low-cost carriers actively seeking access to routes will put pressure on the regulation of international aviation. Current regulations limit their development, and the success of low-cost carriers on the routes they are allowed to fly on raises questions about the wisdom of restricting their access to other routes.

\section{PRIVATE EQUITY}

Airlines in the region are unlikely to be able to survive the competitive pressures that now apply without further injections of equity. Governments will not be able to provide the funding required (or may do so only at high opportunity cost), so their operation depends on private equity. Sources of equity within the region are not likely to be sufficient, and foreign investment will most likely be sought. These considerations are already evident in the process of sale of Polynesian Airlines, discussed above.

The opportunities for foreign investors to enter the markets are limited by current rules on ownership and control in the bilateral agreements. Exploring new rules on ownership that will work within the region and that will be accepted by partners outside the region is a priority. Some options are available from the International Civil Aviation Organization and from the consideration of similar issues in other sectors by the World Trade Organization (in the context of the GATS negotiations). The Pacific Islands Air Services Agreement too has options for relaxing rules on ownership and control some time after implementation, as already noted.

Higher levels of private ownership have the advantage prompting efficiency gains in airline operations and establishing a commercial focus in decisionmaking. This has implications for market performance and the nature of competition in regional markets. It has implications for incentives for cooperation among airlines. It was observed that airline cooperation driven by markets was more likely to be successful than that established by committees of governments. The experience of mixtures of competition and cooperation 
among airlines in other markets is of interest in the transition to higher levels of private (from within and from outside the region) ownership and control.

A further implication of a tighter commercial focus in airlines' boards and managements will be a resistance to meeting obligations imposed by government, to provide particular services for example, without compensation. The immediate policy challenge is to design and implement systems of decisionmaking on the extent of support for network development in the region. Options for taking competitive bids on meeting these targets should also be explored. Techniques for subjecting the proposals to studies of their costs and benefits should also be developed.

Just as private participation in airport infrastructure requires consideration of complementary regulatory reform, so higher levels of private participation in airline operations require consideration of new ways to meet community expectations of service standards.

One of the more important aspects concerns operation of developmental and remote or low-density routes. Several of the routes that the South Pacific airlines fly are apparently loss-making and airlines cross-subsidise these from their profitable routes, such as those to the Pacific Rim countries. Private operators are much less likely to be willing to cross-subsidise chronic lossmaking routes than publicly owned airlines; indeed, their ability to do so could be much reduced by competition from low-cost carriers on hitherto profitable routes. Governments that wish to continue to ensure that these community service routes be served will have to make alternative arrangements to subsidise them. This problem has been faced by many countries, such as Australia, and European regions, that have opened up their airline markets to competition. There is now a growing fund of experience on which the Pacific nations can draw (see ICAO 2005).

Mention has already been made of the opportunities emerging from the availability of new small jet aircraft. Questions remain about the corporate structure in which new services might be provided, and whether they are best installed through existing operators or whether (as evident in other markets) they are managed efficiently in separate corporate structures. If the latter, further questions emerge about the recognition of new operators under air services agreements in the region. Some structures for the adoption of this new technology hinge on access to various 'capacity sharing' models-for example, one suggestion is that aircraft operations be provided by a business which is 
separate from marketing (so each airline buys the capacity it requires from the operating company). Options such as this should be tested in the marketplace, and not adopted by regulation.

A complementary activity to both the assessment of support for community services, and to the examination of new corporate structures associated with technological change, could be the consolidation of data in the region on the existing networks. This would provide opportunities for various parties to undertake an assessment of the gaps in connectivity in the region. There are interests in this matter in both the public and private sectors.

\section{AIRPORT INFRASTRUCTURE}

The traditional approach to supply of airport and other aviation infrastructure has been for the government to provide and operate the infrastructure directly itself. This is usually, though not always on a cost-recovery basis. Ideally, when new investment to expand or improve capacity is proposed, the government will undertake an assessment, such as a cost-benefit analysis, and determine whether the benefits exceed the costs. If they do, it will proceed with the development, ensuring that infrastructure is neither inadequate nor excessive.

In reality, matters are often not so straightforward. Sometimes assessments will indicate that investments are well worthwhile, but funding limitations will delay or prohibit investment. Airports are often regarded as prestige projects, and governments will make investments that create too much capacity, and create facilities that are excessively lavish. Such investments will lead to the airport being costly to finance and operate and the government may later be faced with a funding crisis, or the airport may be forced to set high charges.

The emerging model in the provision of airport infrastructure is for greater participation by the private sector. This participation can happen in varying degrees. Airlines, for example, might operate, and own or lease, terminals. Non-airline firms, including other airports, may own and operate terminals. Alternatively, an airport might be corporatised-retained in public ownership, but required to operate under commercial principles. At the extreme, the airport as a whole might be privatised, either by sale to strategic investors or by floatation on the stock market.

There are several advantages in private involvement (these are similar to those noted above, in the context of airlines). Private investors will have a keen interest in cost efficiency, since their profitability depends on it. Some private 
investors may have more ready access to funds for investment - this is especially relevant for Pacific island countries, whose governments may have difficulty in funding large new investments. Private investors may also be more innovativefor example, they may be able to make more out of the airport's prospects in retail.

The disadvantage is that airports often possess considerable market power, and the private owners will have every incentive to use this power. They will set prices very high, since they will be unchecked by competition. Governments normally recognise this, and handle it by regulation. Thus, in the United Kingdom, when the London airports were privatised, the government set in operation a price-cap system of price regulation. The same happened when Australia privatised its airports, though Australia has since moved to a system of price monitoring with a threat of regulation should the airports be shown to be abusing their market power. New Zealand also has a system of imposing a threat of regulation on the airports, though there is no explicit monitoring.

While regulation can resolve the market power issue, it comes at a price. In particular, regulation tends to distort the incentives for investment. That is, regulation which is effectively cost-based will give rise to excessive investmentairport corporations will be willing to invest excessively, since they are able to pass on excess costs to their customers. Price-cap systems of regulation, which consist of specifying, for an extended period, a maximum price that the corporation can charge, can give rise to inadequate investment. Additional investment will result in higher costs for the airport, but will not yield any additional revenue, since prices are capped. Even when a rigid price cap is not imposed, inadequate investment may be the result of a slow regulatory process, with the regulator being unwilling to approve price increases proposed by the firm to fund investment because it is sceptical of the firm's need to invest or increase prices. Problems of inadequate investment in Australia's infrastructure have been blamed on the regulatory process (Exports and Infrastructure Taskforce 2005).

Whichever direction is chosen by the Pacific island countries, there will be issues to be resolved. If government access to funds for investment is not a problem, continued public ownership and operation is feasible. Governments that own airports will need to give attention to the incentives they are given to keep costs down, and the incentives they are given to assess potential investments rigorously, and only invest in worthwhile projects. 
Alternatively, if countries go down the path of greater private involvement, they will have to come to an explicit resolution of the regulatory issues. The Pacific island countries do not have much by way of regulatory expertise or experience, and setting up extensive regulatory structures, such as those that exist in Australia or the United Kingdom is not likely to be feasible. It may be feasible to develop simple regulatory structures for airports and other aviation infrastructure that is privatised. Alternatively, when assets or whole airports are privatised, the government may be able to restrain the use of market power by imposing conditions in the contract of sale. Certainly, if airports or related assets are privatised without any attention to the market power issues, it is likely that private investors will press governments to accept excessive investment, since the greater the investment, the greater the profits. This will lead to higher user charges and damage to the country's tourism industry.

\section{CONCLUSION}

Geography and population conspire against airline development. There is a familiar list of problems which previous research has identified. That work has also made the point that regulation and policy have made the situation worse.

There are signs, however, of fundamental change in progress, including a lower tolerance for intervention and the financial burdens it creates. New options for doing business are emerging, and some economies, particularly the outer islands, have taken or look likely to take new options for designation of international operations. There are also new technological options, which might make a difference to the economics of high frequency operations, although uncertainties remain in that respect.

Developments of the system within the region are more difficult to anticipate, but progress to higher density and more competitive markets hinges on additions to capacity on the entry and exit routes to the region, and on increasing traffic coming into the region. The stage is already set for that development with the emergence of the low-cost carriers, the introduction of the Pacific Islands Air Services Agreement, plus the emergence of the model of Polynesian Blue.

The next breakthrough would be the entry of Fiji into an integrated regional market, with scope for accession to the arrangement by countries outside the foundation membership. Fiji has been resisting, but there are scenarios in which Fiji would find it advantageous to join the arrangement. 


\section{APPENDIX}

\section{PACIFIC ISLANDS FORUM}

DRAFT DECLARATION OF PRINCIPLES ON REGIONAL TRANSPORT SERVICES

APIA, 6 AUGUST 2004

Recognising that

- the provision and maintenance of regular, reliable and competitive air and shipping services is crucial to Forum island countries;

- changes in the transport sector, including an increasingly competitive market and new international safety and security requirements, have significant implications for aviation and shipping in the Pacific region; and

- Forum island countries have limited technical capacity;

Pacific Island Forum leaders declare the following principles as central to improving the efficiency, effectiveness and sustainability of air and shipping services:

1 Adherence to principles of good governance is crucial to the viability and sustainability of transport services. This includes, but is not limited to:

a) accountability and transparency in financial management, strategic planning, investment decisions, awarding contracts, and board appointments;

b) clear lines of responsibility for shareholders, boards and management; and

c) accessing and acting upon professional advice, including in relation to decisions on infrastructure.

2 Transport services should, wherever possible, be run on a sustainable commercial basis.

a) Where appropriate, this should include corporatisation and/or privatisation of government-owned services.

b) Where transport entities remain in government ownership and are required to perform commercial activities, such entities should be adequately capitalised.

c) Service levels should reflect demand and price should reflect the cost of delivery. 
d) Where subsidies are judged to be necessary to fulfil declared social obligations, these should be open and transparent.

e) Where appropriate, legislated monopolies should be removed with a view to increasing competition.

3 A central responsibility of government in the transport sector should be in establishing and administering regulatory systems.

4 Increased efforts should be made to implement regional or sub-regional solutions to problems in the transport sector through, for example

a) strategic alliances

b) liberalisation of the economic regulatory environment

c) agreement by FICs to regional cabotage, where FICs could benefit from more services and greater competition

d) coordinated approaches to safety and security issues

e) better coordinated airline schedules

f) training and capacity building.

5 Forum member countries need to comply with internationally accepted standards on aviation and maritime security.

6 Donor support should be provided to Forum Island Countries to assist the implementation of transport sector reforms, conditional on a demonstrated commitment to good governance and economically sustainable solutions. 


\section{COMMENT}

David Barber

Improvements in air transport are critical to further Pacific integration. With few exceptions, airline operations in the Pacific are marginal, mostly reliant on government funding and expatriate pilots, managers and engineers. The chapter by Findlay, Forsyth and King provides a useful summary of the intrinsic problems and governance constraints limiting reform of the aviation sector in the Pacific.

Many of these issues are long-standing and well-known. Some constraints are inherently difficult to address - such as remoteness, scale and thinness of routes-but constraints of distance and scale cannot alone explain the ongoing problems of Pacific aviation.

As the authors note, there have been examples of regional resource sharing through code share and other cooperative arrangements but often these have been reactive rather than proactive, or in some cases designed to curtail competition. To date, a regional airline has not been successful simply because of the conflict between commercial objectives and member states' expectations regarding the level of service delivery.

Improved technology (such as more appropriate jet aircrafts) is likely to have an impact on efficiency through a significant reduction in unit operating costs. But technology options are expensive and, realistically, available to only a few Pacific carriers.

Clearly broad issues of governance combined with policy inertia are major limitations to greater integration through reform of the aviation sector. The 
paper identifies a number of areas, including regional aviation agreements/ traffic rights, financial management and privatisation, where progress has been slow to occur. Indeed the level of government involvement in the sector is perhaps the most critical reform issue. Currently, in many island states, government has a role as both operator and as a regulator of aviation, creating a potential for conflict of interest.

If, as the authors indicate, there are opportunities for improvements in efficiency, why is there policy inertia and lack of commitment to genuine reform? Why is there not more regional integration or sharing of resources? Fundamentally, it seems many small island governments do not understand the industry well and/or obtain most of their advice from their airlines. Hence, there are deeply held concerns about the impact of reforms. While there have been many studies of the sector's problems there has been little quantitative analysis of potential winners and losers including in related sectors such as tourism. There are also legitimate concerns about adequacy of service and probably still some issues of nationalism.

The aviation industry is full of optimists. Despite the perennial problems, there is always a new entrant seeking to enter the market. Competition from low-cost carriers and pressures for rationalisation will continue. Most of the changes that have occurred in the sector have been market driven. Change can be managed. The least effective solution is to resist change. 